\title{
Impact of surgical margin width on long- term outcomes for intrahepatic cholangiocarcinoma: a multicenter study
}

Hongzhi Liu ${ }^{1 \dagger}$, Lianku Lin ${ }^{1 \dagger}$, Ziguo Lin ${ }^{1 \dagger}$, Yifan Chen ${ }^{1 \dagger}$, Qizhen Huang ${ }^{1}$, Lei Ding ${ }^{2}$, Jianying Lou ${ }^{3}$, Shuguo Zheng ${ }^{4}$, Xinyu $\mathrm{Bi}^{5}$, Jianming Wang ${ }^{6}$, Wei Guo ${ }^{7}$, Fuyu $\mathrm{Li}^{8}$, Jian Wang ${ }^{9}$, Yamin Zheng ${ }^{10}$, Jingdong $\mathrm{Li}^{11}$, Shi Cheng ${ }^{12}$, Weiping Zhou ${ }^{13}$, Zhangjun Cheng ${ }^{14}$ and Yongyi Zeng ${ }^{1,2^{*}}$

\begin{abstract}
Background: The objective of this study was to investigate the survival outcomes of surgical margin width in intrahepatic cholangiocarcinoma (ICC).

Methods: Between November 2011 and August 2017, patients who underwent hepatectomy for ICC were collected from 13 major hepatopancreatobiliary centers in China. The survival outcomes for patients who underwent wide margin hepatectomy (WMH) were compared with those who underwent narrow margin hepatectomy (NMH) using the 1:1 propensity score matching (PSM).
\end{abstract}

Results: Among 478 included patients, 195 (40.8\%) underwent WMH whereas 283 (59.2\%) underwent NMH. PSM yielded 79 matched patients with similar baseline characteristics. Patients underwent WMH had a significant better OS and DFS compared with those underwent NMH (before PSM: median OS 27 vs 17 months, $P<0.05$; median DFS 15 vs 8 months, $P=0.001$, after PSM: median OS 41 vs 22 months, $p<0.05$; median DFS 16 vs 10 months, $p<0.05$ ). However, subgroup analysis based on the AJCC staging system, WMH could only improve the survival outcomes in AJCC I ICC patients (Stage I: OS, DFS, $P<0.05$ ).

Conclusions: Surgeons should strive to achieve a wide surgical margin for patients with AJCC I ICC to optimize the long-term outcome.

Keywords: Intrahepatic cholangiocarcinoma, Margin width, Overall survival, Disease-free survival

\footnotetext{
* Correspondence: lamp197311@126.com

${ }^{\dagger}$ Hongzhi Liu, Lianku Lin, Ziguo Lin and Yifan Chen are authors contributed equally as first authors.

'Department of Hepatobiliary Surgery, Mengchao Hepatobiliary Hospital of Fujian Medical University, Xihong Road 312, Fuzhou 350025, Fujian, People's Republic of China

${ }^{2}$ College of Biological Science and Engineering, Fuzhou University, Fuzhou, Fujian, China

Full list of author information is available at the end of the article
}

(c) The Author(s). 2021 Open Access This article is licensed under a Creative Commons Attribution 4.0 International License, which permits use, sharing, adaptation, distribution and reproduction in any medium or format, as long as you give appropriate credit to the original author(s) and the source, provide a link to the Creative Commons licence, and indicate if changes were made. The images or other third party material in this article are included in the article's Creative Commons licence, unless indicated otherwise in a credit line to the material. If material is not included in the article's Creative Commons licence and your intended use is not permitted by statutory regulation or exceeds the permitted use, you will need to obtain permission directly from the copyright holder. To view a copy of this licence, visit http://creativecommons.org/licenses/by/4.0/. The Creative Commons Public Domain Dedication waiver (http://creativecommons.org/publicdomain/zero/1.0/) applies to the data made available in this article, unless otherwise stated in a credit line to the data. 


\section{Background}

Cholangiocarcinoma (CCA) is a heterogeneous group of malignancies, which derived from any part of the biliary epithelium [1, 2]. According to the location within the biliary system, CCA can be classified into intrahepatic, perihilar, and distal CCA [3]. Intrahepatic cholangiocarcinoma (ICC) is the second most common malignant tumor in liver, and its incidence has been increasing continuously in the past decades [4]. Surgical resection is the most effective treatment for patients with ICC. However, long-term outcome after radical resection is still unsatisfactory [5, 6]. It has been reported that the current 5-year survival after resection of ICC is only $20 \% \sim 35 \%$ [7-9]. Lots of factors, including tumor characteristics and resection factors, are associated with long-term survival after resection of ICC $[10,11]$. Among them, surgical margin status and width have attracted many attentions of surgeons and researchers.

Surgical margin status has been reported to be associated with overall survival (OS) and achieving R0 resection is the ultimate objective in resection of ICC $[12,13]$. However, the impact of surgical margin width on long-term survival remains controversial. Several studies reported that a gradual better long-term survival was observed as surgical margin width increased [14]. In contrast, some scholars concluded that not all patients with ICC could benefit from a wide margin hepatectomy (WMH) [15]. Assessing the prognostic value of surgical margin width is vital for clinical management of ICC. Given this, we conducted this multicenter study to investigate the impact of surgical margin width on long-term outcomes in ICC patients.

\section{Patients and methods}

\section{Study cohort}

Patients who underwent radical hepatic resection for ICC between November 2011 and August 2017 were identified from a multicenter database that included 13 major hepatopancreatobiliary centers in China (Eastern Hepatobiliary Surgery Hospital of Navy Medical University, Second Hospital Affiliated to Zhejiang University School of Medicine, Mengchao Hepatobiliary Hospital of Fujian Medical University, First Hospital Affiliated to Army Medical University, Cancer Hospital Chinese Academy of Medical Sciences and Peking Union Medical College, Tongji Hospital Affiliated to Tongji Medical College of Huazhong University of Science and Technology, Beijing Friendship Hospital Affiliated to Capital Medical University, West China Hospital of Sichuan University, Renji Hospital Affiliated to Shanghai Jiaotong University School of medicine, Xuanwu Hospital Affiliated to Capital Medical University, Affiliated Hospital of North Sichuan Medical College, Beijing Tiantan Hospital Affiliated to Capital Medical University, Zhongda Hospital Southeast University). Diagnosis of all enrolled ICC patients were histopathologically confirmed. R0 resection was defined as macroscopic and microscopic removal of all tumors [16]. Patients who

Patients underwent liver resection for ICC $\quad(n=562)$

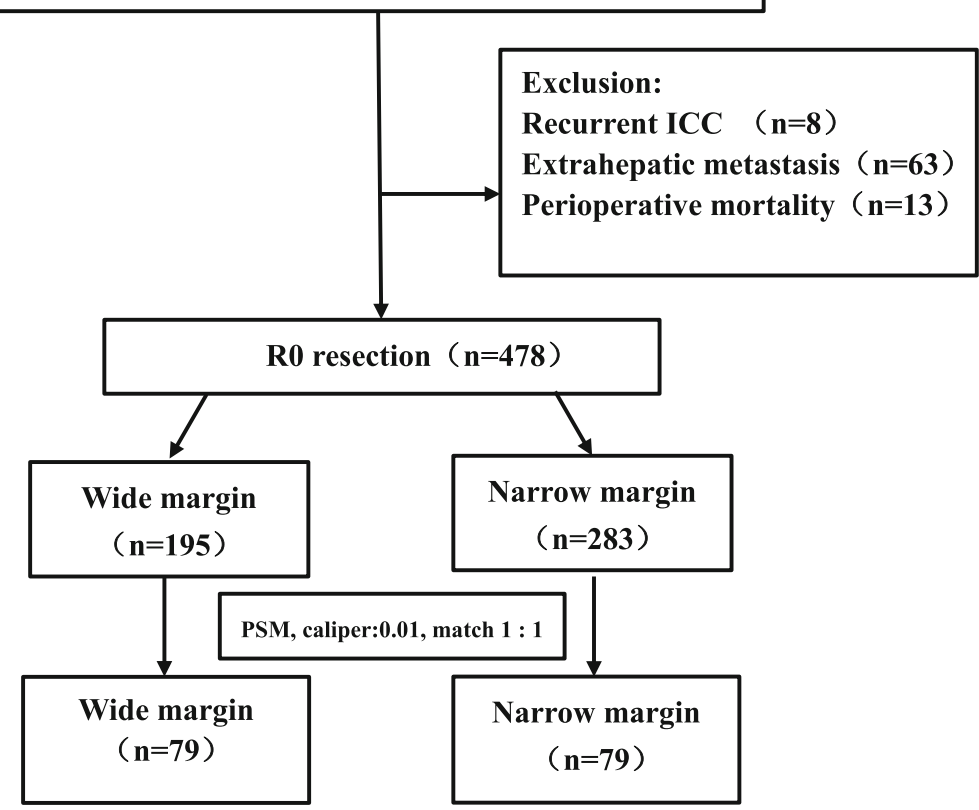

Fig. 1 Flowchart of patients' enrollment 
Table 1 Clinicopathological characteristics before and after PSM

\begin{tabular}{|c|c|c|c|c|c|c|}
\hline \multirow{3}{*}{ Gender } & \multicolumn{3}{|l|}{ Before PSM } & \multicolumn{3}{|l|}{ After PSM } \\
\hline & $\begin{array}{l}\text { Wide } \\
(n=195)\end{array}$ & $\begin{array}{l}\text { Narrow } \\
(n=283)\end{array}$ & $P$-Value & $\begin{array}{l}\text { Wide } \\
(n=79)\end{array}$ & $\begin{array}{l}\text { Narrow } \\
(n=79)\end{array}$ & $P$-Value \\
\hline & & & & & & \\
\hline & $103(52.8 \%)$ & $184(65.0 \%)$ & 0.010 & $51(64.6 \%)$ & 47 (59.5\%) & 0.623 \\
\hline Female & $92(47.2 \%)$ & 99 (35.0\%) & & $28(35.4 \%)$ & 32 (40.5\%) & \\
\hline \multicolumn{7}{|l|}{ Age } \\
\hline$\leq 60$ years & 115(59.0\%) & $177(62.5 \%)$ & 0.489 & $42(53.2 \%)$ & $50(63.3 \%)$ & 0.259 \\
\hline$>60$ years & $80(41.0 \%)$ & $106(7.5 \%)$ & & $37(46.8 \%)$ & 29(36.7\%) & \\
\hline \multicolumn{7}{|l|}{$\mathrm{HBsAg}$} \\
\hline Negative & $144(73.8 \%)$ & $184(65.0 \%)$ & 0.052 & $55(69.6 \%)$ & $59(74.7 \%)$ & 0.594 \\
\hline Positive & $51(26.2 \%)$ & 99 (35.0\%) & & $24(30.4 \%)$ & $20(25.3 \%)$ & \\
\hline \multicolumn{7}{|l|}{ CA19-9 } \\
\hline$\leq 200 \mathrm{U} / \mathrm{mL}$ & $136(69.7 \%)$ & $253(89.4 \%)$ & $<0.001$ & 63(79.7\%) & $65(82.3 \%)$ & 0.839 \\
\hline$>200 \mathrm{U} / \mathrm{mL}$ & 59 (30.3\%) & $30(10.6 \%)$ & & $16(20.3 \%)$ & $14(17.7 \%)$ & \\
\hline \multicolumn{7}{|l|}{ CEA } \\
\hline$\leq 5 \mu \mathrm{g} / \mathrm{L}$ & $125(64.1 \%)$ & $234(82.7 \%)$ & $<0.001$ & $56(70.9 \%)$ & $56(70.9 \%)$ & 1.000 \\
\hline$>5 \mu \mathrm{g} / \mathrm{L}$ & 70 (35.9\%) & 49 (17.3\%) & & 23(29.1\%) & 23(29.1\%) & \\
\hline \multicolumn{7}{|l|}{ Blood loss } \\
\hline$\leq 400 \mathrm{~mL}$ & $141(72.3 \%)$ & 229(80.9\%) & 0.036 & $61(77.2 \%)$ & $57(72.2 \%)$ & 0.583 \\
\hline$>400 \mathrm{~mL}$ & $54(27.7 \%)$ & $54(19.1 \%)$ & & 18(22.8\%) & $22(27.8 \%)$ & \\
\hline \multicolumn{7}{|l|}{ Transfusion } \\
\hline No & 148(75.9\%) & 246(86.9\%) & 0.003 & 60(75.9\%) & $61(77.2 \%)$ & 1.000 \\
\hline Yes & $47(24.1 \%)$ & $37(13.1 \%)$ & & $19(24.1 \%)$ & 18(22.8\%) & \\
\hline \multicolumn{7}{|c|}{ Laparoscopic approach } \\
\hline No & $163(83.6 \%)$ & $281(99.3 \%)$ & $<0.001$ & $76(96.2 \%)$ & 77 (97.5\%) & 1.000 \\
\hline Yes & $32(16.4 \%)$ & $2(0.7 \%)$ & & $3(3.8 \%)$ & $2(2.5 \%)$ & \\
\hline \multicolumn{7}{|c|}{ Major hepatectomy } \\
\hline No & $72(36.9 \%)$ & $80(28.3 \%)$ & 0.058 & $32(40.5 \%)$ & $31(39.2 \%)$ & 1.000 \\
\hline Yes & $123(63.1 \%)$ & 203(71.7\%) & & $47(59.5 \%)$ & $48(60.8 \%)$ & \\
\hline \multicolumn{7}{|l|}{ Complications } \\
\hline No & $137(70.3 \%)$ & $233(82.3 \%)$ & 0.003 & $60(75.9 \%)$ & $59(74.7 \%)$ & 1.000 \\
\hline Yes & $58(29.7 \%)$ & $50(17.7 \%)$ & & $19(24.1 \%)$ & $20(25.3 \%)$ & \\
\hline \multicolumn{7}{|l|}{ Tumor size } \\
\hline$\leq 5 \mathrm{~cm}$ & $86(44.1 \%)$ & $94(33.2 \%)$ & 0.020 & $37(46.8 \%)$ & $34(43.0 \%)$ & 0.749 \\
\hline$>5 \mathrm{~cm}$ & $109(55.9 \%)$ & $189(66.8 \%)$ & & $42(53.2 \%)$ & $45(57.0 \%)$ & \\
\hline \multicolumn{7}{|l|}{ Tumor number } \\
\hline Single & $163(83.6 \%)$ & $181(64.0 \%)$ & $<0.001$ & $61(77.2 \%)$ & $60(75.9 \%)$ & 1.000 \\
\hline Multiple & $32(16.4 \%)$ & $102(36.0 \%)$ & & $18(22.8 \%)$ & $19(24.1 \%)$ & \\
\hline \multicolumn{7}{|c|}{ Lymph node invasion } \\
\hline No & $140(71.8 \%)$ & $250(88.3 \%)$ & $<0.001$ & $67(84.8 \%)$ & $69(87.3 \%)$ & 0.818 \\
\hline Yes & $55(28.2 \%)$ & $33(11.7 \%)$ & & $12(15.2 \%)$ & $10(12.7 \%)$ & \\
\hline \multicolumn{7}{|l|}{ Mass-forming } \\
\hline No & $38(19.5 \%)$ & $116(41.0 \%)$ & $<0.001$ & 28(35.4\%) & $19(24.1 \%)$ & 0.164 \\
\hline Yes & $157(80.5 \%)$ & 167 (59.0\%) & & $51(64.6 \%)$ & $60(75.9 \%)$ & \\
\hline
\end{tabular}


Table 1 Clinicopathological characteristics before and after PSM (Continued)

\begin{tabular}{|c|c|c|c|c|c|c|}
\hline & \multicolumn{3}{|l|}{ Before PSM } & \multicolumn{3}{|l|}{ After PSM } \\
\hline & $\begin{array}{l}\text { Wide } \\
(n=195)\end{array}$ & $\begin{array}{l}\text { Narrow } \\
(n=283)\end{array}$ & $P$-Value & $\begin{array}{l}\text { Wide } \\
(n=79)\end{array}$ & $\begin{array}{l}\text { Narrow } \\
(n=79)\end{array}$ & $P$-Value \\
\hline \multicolumn{7}{|c|}{ Tumor differentiation } \\
\hline Well \&Moderate & $139(71.3 \%)$ & $236(83.4 \%)$ & 0.002 & $64(81.0 \%)$ & $60(75.9 \%)$ & 0.561 \\
\hline Poor & $56(28.7 \%)$ & $47(16.6 \%)$ & & 15(19.0\%) & $19(24.1 \%)$ & \\
\hline \multicolumn{7}{|l|}{ Satellite } \\
\hline No & $170(87.2 \%)$ & $181(64.0 \%)$ & $<0.001$ & $65(82.3 \%)$ & $62(78.5 \%)$ & 0.689 \\
\hline Yes & $25(12.8 \%)$ & $102(36.0 \%)$ & & 14(17.7\%) & $17(21.5 \%)$ & \\
\hline \multicolumn{7}{|l|}{ MVI } \\
\hline No & $165(84.6 \%)$ & $254(89.8 \%)$ & 0.124 & 72(91.1\%) & $68(86.1 \%)$ & 0.453 \\
\hline Yes & $30(15.4 \%)$ & $29(10.2 \%)$ & & $7(8.9 \%)$ & $11(13.9 \%)$ & \\
\hline \multicolumn{7}{|l|}{ Perineural invasion } \\
\hline No & $164(84.1 \%)$ & $261(92.2 \%)$ & 0.008 & $66(83.5 \%)$ & $69(87.3 \%)$ & 0.652 \\
\hline Yes & $31(15.9 \%)$ & $22(7.8 \%)$ & & $13(16.5 \%)$ & 10(12.7\%) & \\
\hline \multicolumn{7}{|l|}{ p-AT } \\
\hline No & $141(72.3 \%)$ & $240(84.8 \%)$ & 0.001 & $64(81.0 \%)$ & $66(83.5 \%)$ & 0.835 \\
\hline Yes & $54(27.7 \%)$ & $43(15.2 \%)$ & & 15(19.0\%) & $13(16.5 \%)$ & \\
\hline
\end{tabular}

Abbreviations: PSM propensity score matching, CEA carcinoembryonic antigen, CA19-9 carbohydrate antigen 19-9, HBsAg hepatitis B surface antigen, MVI microvascular invasion, $p-A T$ postoperative adjuvant therapy

underwent palliative resection and patients with positive surgical margin, mortality within 1 month of surgery, peritoneal seeding, distant metastasis and incomplete information were excluded. This study was approved by the institutional review board of each participating center.

\section{Data collection}

Data, including patient demographics, perioperative variables, tumor-related clinicopathological characteristics, and follow-up data, were collected using a standardized data sheet. The resectability of the tumor was determined according to the performance status, liver function reserve and tumor imaging features of the patients before surgery. Operative information included the type of hepatectomy, receipt of lymph node dissection, margin status, intraoperative blood loss, transfusion. Postoperative pathological variables included tumor number, size, morphology, grade, vascular/perineural/biliary/adjacent organ invasion, lymph node metastasis, satellite nodules, and surgical margin width. Adjuvant therapy was performed after assessing by a multidisciplinary team. Tumor staging was evaluated according to the 8th edition of the AJCC staging system [17].

Patients were divided into two groups according to the surgical margin width: narrow $(<10 \mathrm{~mm})$ and wide $(\geq 10 \mathrm{~mm})$.

\section{Follow-up}

Patients were regularly followed up every 3-6 months after surgery, during which serum carbohydrate antigen 19-9 (CA19-9) and abdominal CT or MRI were routinely performed. The endpoints of this study were OS and DFS. OS was defined as the interval between the date of surgery and the date of death from any cause or the date of the last follow-up. Disease-free survival (DFS) was defined as the interval between the date of surgery and the first recurrence or the last follow-up.

\section{Statistical analysis}

Categorical variables were expressed as number and percentages, and differences were compared by Chi-square test or Fisher's exact test. OS and DFS were analyzed by the Kaplan-Meier method, and the log-rank test was used for between-group comparisons. The Cox proportional hazards model was used to identify risk factors of OS and DFS, and variables with statistically significant differences in the univariate analysis were included in the multivariate analysis.

Since patients who underwent WMH and narrow margin hepatectomy $(\mathrm{NMH})$ were not randomly distributed, propensity score matching (PSM) was used to minimize selection bias. The caliper was set at 0.01 , and an optimal match ratio of 1:1 was used according to the nearest neighbor method. Statistical analyses were performed 
using $\mathrm{R}$ 3.6.1. A two-tailed $P$ value less than 0.05 was considered statistically significant.

\section{Results}

\section{Patient characteristics}

Figure 1 presented the flowchart of patients' enrollment. The median age of the enrolled 478 patients was 58 years (IQR, 49-64 years) and 287 were male (60.0\%). The median tumor size of patients was 6.7 $\mathrm{cm}$, and the majority were single tumor $(n=344$, 72.0\%). In total, 283 (59.2\%) underwent $\mathrm{NMH}$, whereas 195 (40.8\%) underwent WMH. Several factors, including gender, CA19-9, CEA, blood loss, transfusion, tumor diameter, tumor number, lymph node invasion, gross type, differentiation, satellite, perineural invasion and adjuvant therapy, were associated with margin width (Table 1). Wide margin resection was more frequently performed among patients had a small, single and CA19-9 level raised tumor, and more frequently performed by laparoscopic approach. While age, HBsAg, MVI, and major hepatectomy have no difference between the two groups $(P>0.05)$. Propensity score matching was performed for the above factors that might influence the prognostic analysis. After 1:1 PSM, there were 79 of the 195 WMH patients were matched with 79 of the $283 \mathrm{NMH}$ patients, and all baseline characteristics were compared between the groups.

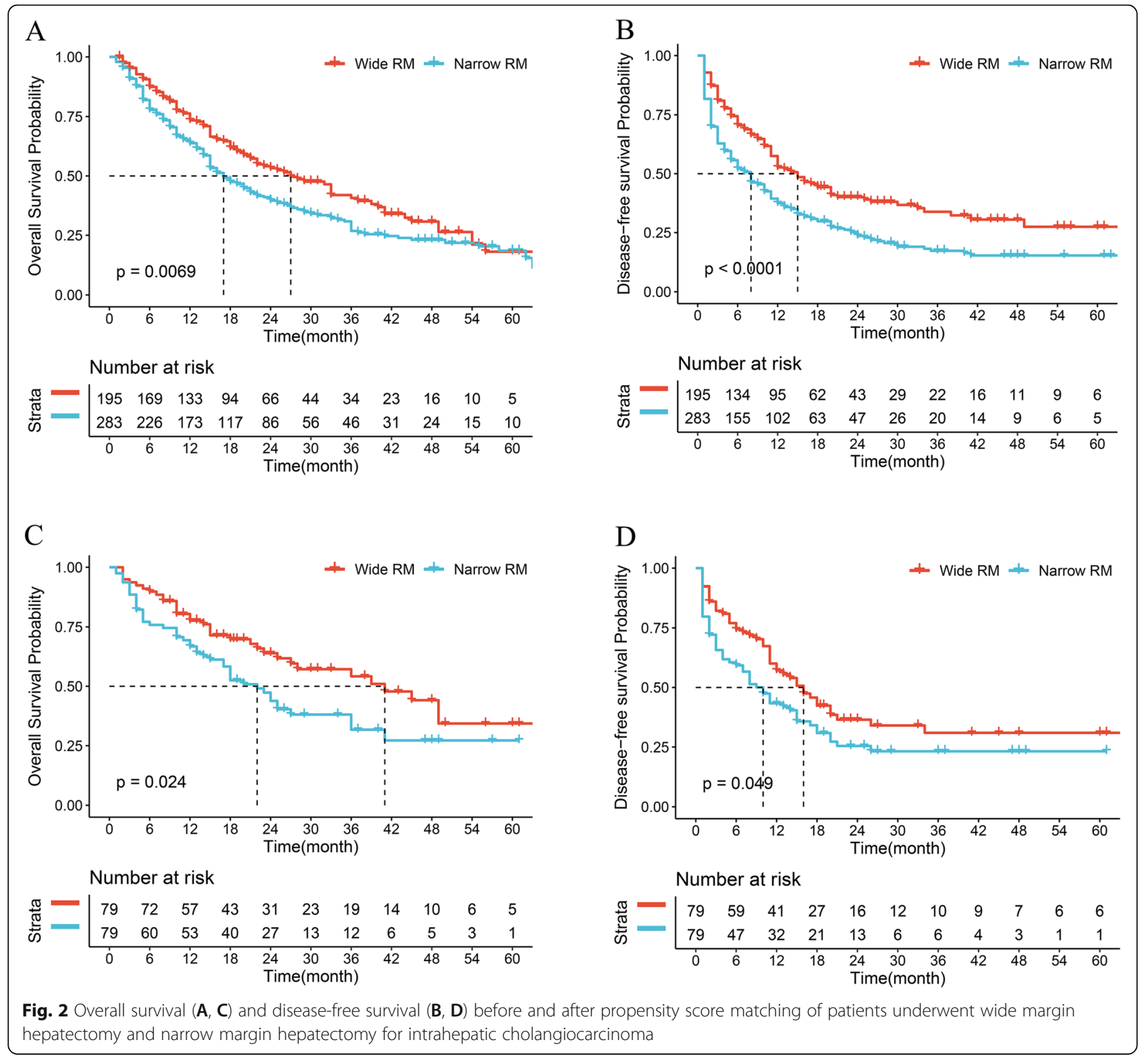


Impact of surgical margin width and long-term outcomes Among all patients, overall median, 1-, 3-, and 5-year OS was 22 months, 69.20, 36.60, and $26.70 \%$, respectively. Overall median, 1-, 3-, and 5-year DFS was 21 months, 59.80, 41.20, and $37.60 \%$, respectively. Patients underwent WMH had a longer median OS compared with patients undergoing NMH (33 vs 18 months, $P<0.05$; Fig. 2 A). The 1 -, 3-, and 5 -year OS in WMH were also higher significantly than in the $\mathrm{NMH}(76.10 \%$, vs $66.22,56.10 \%$ vs $39.86,50.24 \%$ vs $37.16 \%$, all $p<0.05$, respectively). Meanwhile, patients underwent WMH had a longer median DFS compared with patients undergoing NMH (16 vs 8 months, $P<0.001$; Fig. 2 B). The 1-, 3-, and 5-year DFS in WMH were also higher significantly than in the NMH (58.05\% vs $40.88,45.85 \%$ vs 28.04 , $36.59 \%$ vs $27.36 \%$, all $p<0.001$, respectively).

After 1:1 PSM, the median, 1-, 3-, and 5-year OS of patients in the WMH were still better than that in $\mathrm{NMH}$
(40 vs 21 months, $81.51 \%$ vs $67.23,63.87 \%$ vs 40.34 , $57.14 \%$ vs $40.34 \%$, all $p<0.05$, respectively; Fig. 2 C). Similarly, the median, 1-, 3-, and 5-year DFS of patients in the WMH were also better than that in $\mathrm{NMH}$ (17 vs 9 months, $60.50 \%$ vs $45.38,46.22 \%$ vs $34.45,45.38 \%$ vs $33.61 \%$, all $\mathrm{p}<0.05$, respectively; Fig. 2 D).

\section{Univariate and multivariate cox analyses of OS and DFS in patients with intrahepatic cholangiocarcinoma}

Before PSM, univariate analysis identified surgical margin width was associated with OS and DFS (all $P<0.05$ ). Additionally, multivariable analysis showed that surgical margin width was an independent prognostic factor affecting OS and DFS (Table S1). After PSM, univariate analysis identified surgical margin width was associated with OS and DFS (all $\mathrm{P}<0.05$ ). However, multivariable analysis showed that surgical margin width was an

Table 2 Univariate and multivariate analysis of overall survival and disease-free survival for patients with intrahepatic cholangiocarcinoma after PSM

\begin{tabular}{|c|c|c|c|c|c|c|c|c|c|}
\hline \multirow[t]{3}{*}{ Characteristic } & \multirow[t]{3}{*}{ Variables } & \multicolumn{4}{|l|}{ OS } & \multicolumn{4}{|l|}{ DFS } \\
\hline & & \multicolumn{2}{|l|}{$\begin{array}{l}\text { Univariate } \\
\text { analysis }\end{array}$} & \multicolumn{2}{|l|}{$\begin{array}{l}\text { Multivariate } \\
\text { analysis }\end{array}$} & \multicolumn{2}{|l|}{$\begin{array}{l}\text { Univariate } \\
\text { analysis }\end{array}$} & \multicolumn{2}{|l|}{$\begin{array}{l}\text { Multivariate } \\
\text { analysis }\end{array}$} \\
\hline & & HR $(95 \% C l)$ & $\begin{array}{l}P \\
\text { value }\end{array}$ & HR $(95 \% C l)$ & $\begin{array}{l}P \\
\text { value }\end{array}$ & HR $(95 \% C l)$ & $\begin{array}{l}P \\
\text { value }\end{array}$ & $\mathrm{HR}(95 \% \mathrm{Cl})$ & $\begin{array}{l}P \\
\text { value }\end{array}$ \\
\hline Gender & Female vs Male & $0.72(0.45-1.14)$ & 0.158 & & & $0.77(0.51-1.16)$ & 0.217 & & \\
\hline Age (y) & $\leq 60$ vs $>60$ & $0.92(0.59-1.43)$ & 0.706 & & & $0.71(0.48-1.06)$ & 0.098 & & \\
\hline $\mathrm{HBsAg}$ & Negative vs Positive & $1.08(0.67-1.75)$ & 0.750 & & & $1.08(0.70-1.66)$ & 0.738 & & \\
\hline ECOG score & $\leq 2$ vs $>2$ & $1.00(0.64-1.55)$ & 0.986 & & & $0.80(0.54-1.18)$ & 0.255 & & \\
\hline CA19-9 (U/ml) & $\leq 200$ vs $>200$ & $1.23(0.71-2.14)$ & 0.458 & & & $0.88(0.53-1.47)$ & 0.625 & & \\
\hline CEA (ng/ml) & $\leq 5$ vs $>5$ & $1.03(0.63-1.67)$ & 0.912 & & & $0.91(0.59-1.39)$ & 0.653 & & \\
\hline Blood loss (ml) & $\leq 400$ vs $>400$ & $1.02(0.61-1.71)$ & 0.947 & & & $0.74(0.46-1.19)$ & 0.216 & & \\
\hline Transfusion & No vs Yes & $1.15(0.69-1.90)$ & 0.600 & & & $0.61(0.37-1.02)$ & 0.058 & & \\
\hline $\begin{array}{l}\text { Laparoscopic } \\
\text { approach }\end{array}$ & No vs Yes & $1.39(0.34-5.70)$ & 0.644 & & & $0.74(0.18-3.00)$ & 0.671 & & \\
\hline Major hepatectomy & No vs Yes & $1.34(0.84-2.15)$ & 0.215 & & & $1.02(0.69-1.52)$ & 0.920 & & \\
\hline Complications & No vs Yes & 1.06(0.65-1.73) & 0.809 & & & $0.87(0.56-1.37)$ & 0.562 & & \\
\hline $\begin{array}{l}\text { Resection margin } \\
(\mathrm{cm})\end{array}$ & $\leq 1$ vs $>1$ & $1.65(1.06-2.58)$ & 0.026 & $1.60(1.03-2.50)$ & 0.039 & $1.49(1.01-2.20)$ & 0.046 & & \\
\hline Tumor size (cm) & $\leq 5$ vs $>5$ & $1.33(0.85-2.08)$ & 0.214 & & & $1.15(0.77-1.70)$ & 0.497 & & \\
\hline Tumor number & Solitary vs Multiple & $1.31(0.81-2.12)$ & 0.267 & & & $1.14(0.73-1.80)$ & 0.558 & & \\
\hline $\begin{array}{l}\text { Lymph node } \\
\text { invasion }\end{array}$ & No vs Yes & $2.03(1.15-3.57)$ & 0.014 & $2.24(1.27-3.95)$ & 0.005 & $1.15(0.65-2.02)$ & 0.638 & & \\
\hline Mass-forming & No vs Yes & $1.17(0.73-1.87)$ & 0.524 & & & $1.33(0.87-2.05)$ & 0.187 & & \\
\hline $\begin{array}{l}\text { Tumor } \\
\text { differentiation }\end{array}$ & $\begin{array}{l}\text { Well \&Moderate vs } \\
\text { Poor }\end{array}$ & $1.33(0.85-2.08)$ & 0.214 & & & $0.80(0.48-1.34)$ & 0.399 & & \\
\hline Satellite & No vs Yes & $1.27(0.77-2.11)$ & 0.352 & & & $1.32(0.84-2.09)$ & 0.231 & & \\
\hline $\mathrm{MVI}$ & No vs Yes & $2.03(1.12-3.69)$ & 0.02 & & & $2.42(1.39-4.22)$ & 0.002 & $2.67(1.50-4.74)$ & 0.001 \\
\hline Perineural invasion & No vs Yes & $0.94(0.50-1.79)$ & 0.860 & & & $0.69(0.38-1.26)$ & 0.232 & & \\
\hline p-AT & No vs Yes & $0.38(0.18-0.83)$ & 0.016 & $0.39(0.18-0.85)$ & 0.018 & $0.73(0.43-1.24)$ & 0.244 & & \\
\hline
\end{tabular}

Abbreviations: PSM propensity score matching, CEA carcinoembryonic antigen, CA19-9 carbohydrate antigen 19-9, HBsAg hepatitis B surface antigen, MVI microvascular invasion, $p$-AT postoperative adjuvant therapy, OS overall survival, DFS disease-free survival, $H R$ hazard ratio 


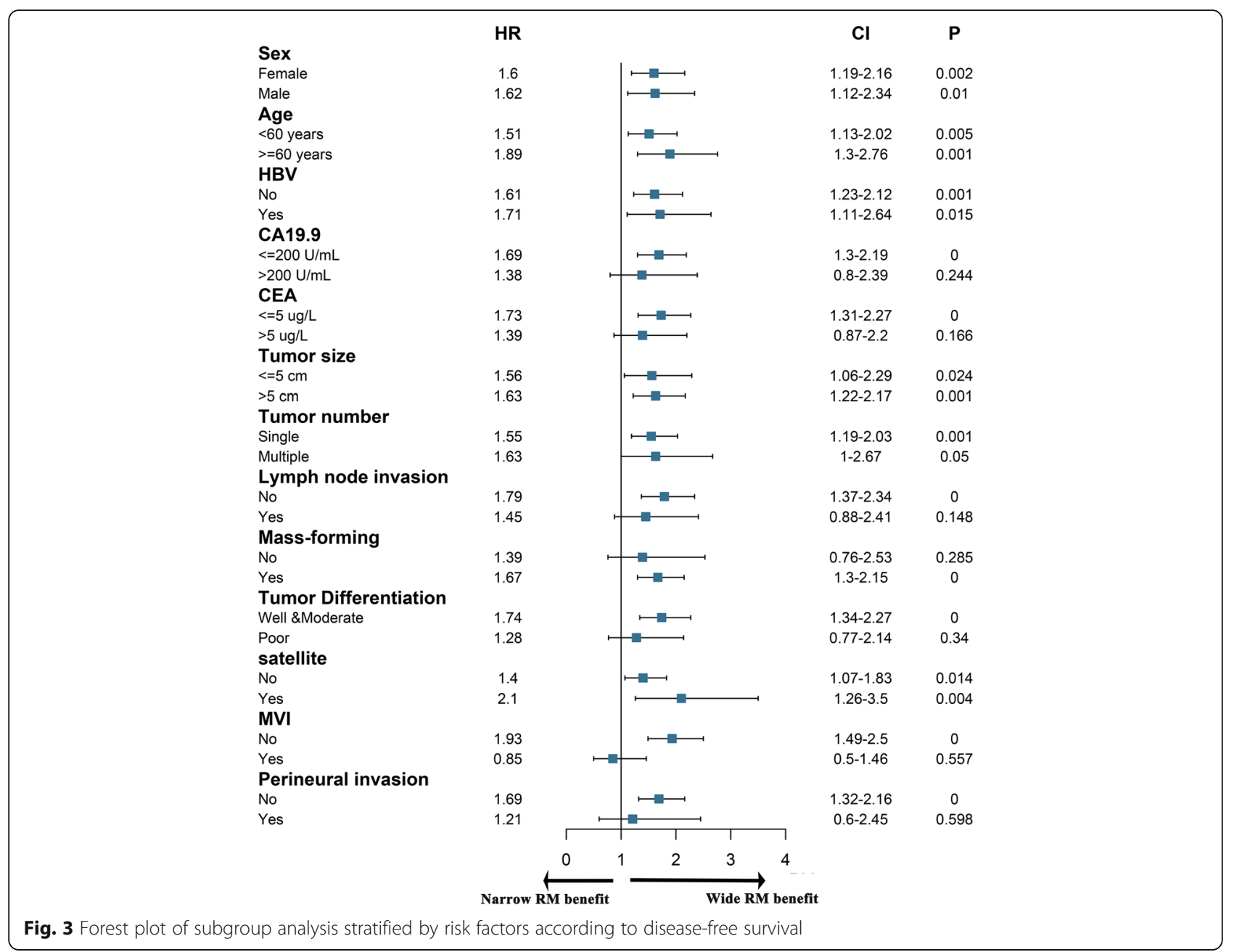

independent prognostic factor affecting OS but not DFS (Table 2).

\section{Subgroup analysis based on clinicopathologic feature}

To identify the optimal ICC patients for WMH, subgroup analysis was conducted based on clinicopathologic feature. As shown in Fig. 3, The following factors may benefit DFS of the patients who underwent WMH: CA199 $\leq 200 \mathrm{U} / \mathrm{mL}, \mathrm{CEA} \leq 5 \mu \mathrm{g} / \mathrm{L}$, no lymph node metastasis, MF type, mild tumor differentiation, no MVI, and no perineural invasion (Fig. 3). The following factors may benefit OS of the patients who underwent WMH: female, $\geq 60$ years, non-HBV infection, CA199 $\leq 200 \mathrm{U} /$ $\mathrm{mL}, \mathrm{CEA} \leq 5 \mu \mathrm{g} / \mathrm{L}$, tumor size $>5 \mathrm{~cm}$, no lymph node metastasis, MF type, mild tumor differentiation, no MVI, and no perineural invasion (Fig. 4).

\section{Subgroup analysis based on AJCC staging system}

To comprehensively understand the relationship between clinicopathological features and surgical margin, subgroup analysis was further conducted based on the 8th AJCC staging system. In total, there were 258 (54.0\%), 132 (27.6\%), and 88 (18.4\%) patients were assigned to stage I / II / III groups. The impact of the surgical margin width depended on the context. As for stage I, patients underwent $\mathrm{NMH}$ had an inferior OS and DFS than patients underwent WMH (median OS was 37 vs 22 months, $P<0.05$, Fig. $5 \mathrm{~A}$; median DFS was 20 vs 11 months, $P<0.05$, Fig. 5 D). However, we did not observe a significant difference between the $\mathrm{WMH}$ and $\mathrm{NMH}$ in terms of OS and DFS for ICC patients with stage II or III (Stage II: median OS was 15 vs 14 months, $P=0.63$, Fig. $5 \mathrm{~B}$; median DFS was 6 vs 4 months, $P=0.45$, Fig. 5 E; Stage III: median OS was 16 vs 12 months, $P=0.20$, Fig. $5 \mathrm{C}$; median DFS was 10 vs 5 months, $P=0.16$, Fig. $5 \mathrm{~F})$.

\section{Discussion}

For ICC, liver resection remains the most effective treatment strategy at present. While surgical margin status was identified as a prognostic factor, the 


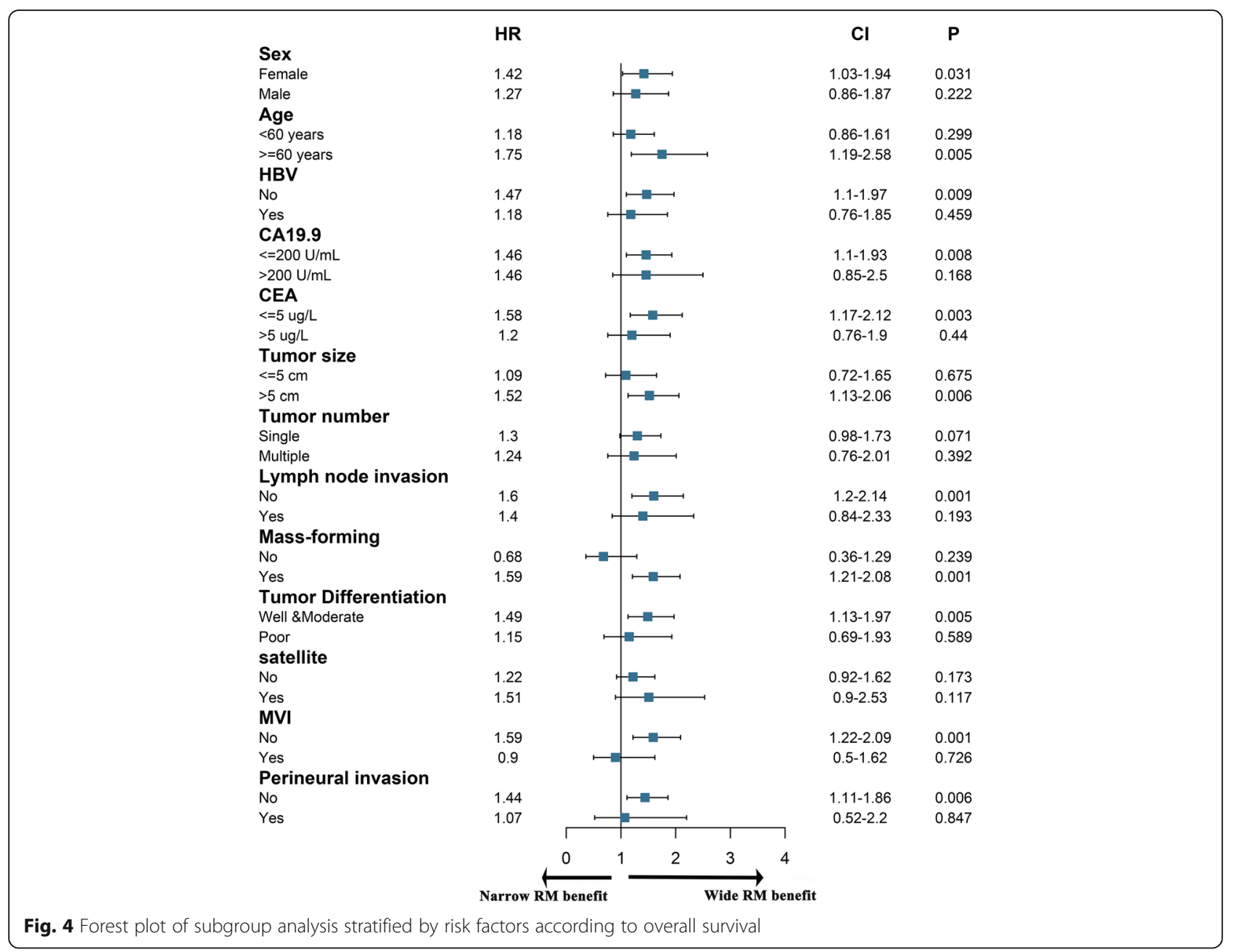

impact of surgical margin width on long-term outcome following R0 resection of ICC has been less well studied and remains controversial. In addition, the biological characteristics of high heterogeneity determined the ICC patients with different clinicopathological characteristics have significantly different prognostic outcome $[18,19]$. Therefore, it is necessary to further explore and discuss the prognostic value of WMH in ICC patients with different characteristics and stages. In this study, we conducted a PSM analysis using multicenter ICC data, and discovered that patients underwent WMH had better prognosis outcomes compared with patients undergoing $\mathrm{NMH}$; however, subgroup analysis found that WMH improved OS and DFS in AJCC I patients, but did not improve long-term prognosis in AJCC II-III patients. To our knowledge, this is the first study to evaluate the impact of surgical margin width on the outcome of ICC with different characteristics and stages.
Previous studies have offered varied views on whether margin width improves the long-term prognosis of intrahepatic cholangiocarcinoma. Ribero $\mathrm{M}$ et al. [20] found that margin width had no effect on OS $(P=0.61)$ and DFS $(P>0.05)$ in patients with negative margins. In addition, Watanabe et al. [15] showed that wide margins did not improve the long-term prognosis of all patients undergoing R0 hepatectomy. However, Spolverato et al. [12] showed that margin width was positively correlated with prognosis, and the prognosis was better when margin width $>1 \mathrm{~cm}$. Besides, Farges et al. [14] suggested that margin width $<5 \mathrm{~mm}$ was an independent risk factor for poor prognosis. A meta-analysis showed a consistent result that WMH could benefit long-term survival in patients with ICC [21].

Although it is still controversial whether WMH improves prognosis, several studies have shown that margin distance is positively correlated with improved prognosis, and the wider the surgical margin, the greater the prognostic improvement [12, 14, 22]. 


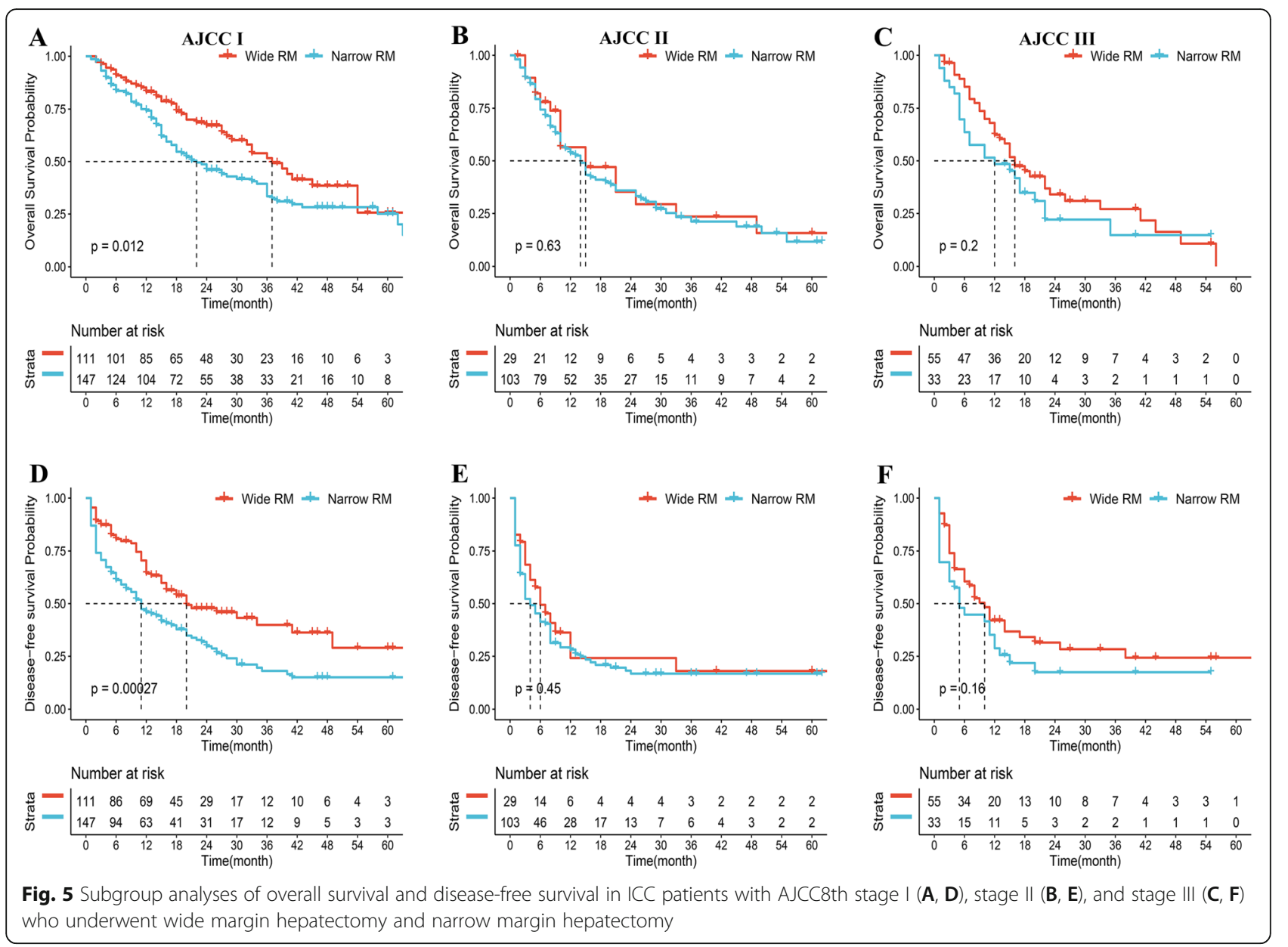

In this study, it was further found that this improvement is undermined by an increase in the tumor stage when the surgical margin $\geq 1 \mathrm{~cm}$, and ICC patients with stage II-III did not benefit from WMH. We believe that this is mainly due to the highly invasive characteristics of ICC. Compared with hepatocellular carcinoma, ICC has more aggressive biological characteristics, such as bile duct invasion, nerve invasion and lymph node metastasis, which are hard to be eliminated by hepatectomy alone. At present, AJCC TNM staging is the most commonly used prognostic system for ICC, and higher AJCC staging is associated with more aggressive invasion [23].

In patients with stage II of AJCC, multiple tumors usually reflect intrahepatic metastasis, and a study of European Network for the Study of Cholangiocarcinoma (ENS-CCA) has shown that the prognosis of these patients is as poor as that of patients with extrahepatic metastasis [24]. Besides, ICC with vascular invasion is also classified as stage II, which is also reported to be the independent risk factor of prognosis for patients with ICC $[18,25]$. ICC with stage III represents an extensive range of invasion and metastasis, including extrahepatic invasion and lymph node metastasis. Patients with stage II-III are likely to benefit from a R0 resection,[26] however, our result showed that a wider surgical margin could hard further improve prognosis of these patients. Several previous studies conducted subgroup analysis to evaluated the impact of WMH on the outcome of ICC. Studies of Farges et al. and Watanabe et al. documented that WMH could not provide benefit for patients with lymph node metastasis [14, 15]. Similarly, we found patients with lymph node metastasis had no benefit from WMH. This reflects that lymph node metastasis was a factor that played a fatal role for the outcome of patients with ICC and WMH is not enough to improve the prognosis of these patients. In addition to lymph node metastasis, many other factors may affect the prognosis of hepatectomy. In this study, we found WMH had a longer OS and DFS than NMH in patients with CA199 $200 \mathrm{U} / \mathrm{mL}, \mathrm{CEA} \leq 5 \mu \mathrm{g} / \mathrm{L}$, MF type, mild tumor differentiation, no MVI, and no perineural invasion.

In clinical practice, the operation of WMH in ICC patients would be affected by many factors, including 
inadequate residual liver volume, tumors adherent to major vessels. Some researchers suggested preoperative portal vein embolization could improve the resectability and increase the percent of WMH in these patients, although the following surgical delay may cause tumor progression [14]. Besides, approaches such as extended resection and vascular reconstruction were considered to improve outcome further [22, 27]. Of note, aggressive approaches used to achieve a WMH may lead to an increase in adverse events, such as liver failure and massive bleeding [15]. In this study, a higher rate of intraoperative blood loss, transfusion, and postoperative complication were observed in WMH group. Given that, we suggested that wide surgical margin is recommended to improve the long-term outcome for ICC patients with AJCC stage I on the basis of adequate preoperative preparation and ensuring surgical safety. As for patients with stage II or III, WMH alone is not sufficient to improve the survival, and adjuvant therapy and other effective treatments may still needed.

There are several limitations that should be acknowledged when interpreting this study. First, this was a retrospective study and selection bias may have been present. To mitigate this bias, we conducted PSM to match the prognostic factors between the two groups. Second, detailed surgical margin width was lacked in this database, and further subgroup analyses focused on the influence of different width groups were affected. Third, due to the data of surgical margin width was from pathological exam, the measurement of it may affected by shrinkage of pathological specimens during the production process. Therefore, it is necessary to carry out prospective multicentre studies on the basis of standard intraoperative measurement of margin width.

\section{Conclusions}

In conclusion, we suggest surgeons should strive to achieve a wide surgical margin for ICC patients with AJCC stage I to optimize the long-term outcome. As for ICC patients with AJCC stage II or III, WMH alone could not improve the survival and more effective treatments are still needed.

\section{Supplementary Information}

The online version contains supplementary material available at https://doi. org/10.1186/s12885-021-08560-7.

Additional file 1: Table S1. Univariate and multivariate analysis of overall survival and disease-free survival for patients with intrahepatic cholangiocarcinoma before PSM.

\section{Acknowledgements}

Not Applicable.

\section{Authors' contributions}

Yongyi Zeng, Hongzhi Liu contributed to the study conception and design. Hongzhi Liu, Lianku Lin, Ziguo Lin, Yifan Chen, Qizhen Huang and Lei Ding contributed to analysis and interpretation of data. Yongyi Zeng, Jianying Lou, Shuguo Zheng, Xinyu Bi, Jianming Wang, Wei Guo, Fuyu Li, Jian Wang, Yamin Zheng, Jingdong Li, Shi Cheng and Zhangjun Cheng and Weiping Zhou contributed to offering the data. Hongzhi Liu, Lianku Lin and Ziguo Lin drafting the manuscript. Yongyi Zeng contributed to revising the article, critical revision, and final approval. All authors read and approved the final manuscript.

\section{Funding}

This study was supported by Startup Fund for Scientific Research, Fujian Medical University (2019QH1294), Fujian provincial health research talent training project (2019-1-85), and Fuzhou Science and Technology Bureau project (2020-WS-92). The funding bodies had no role in the study design, data collection and analysis, interpretation, or in writing the manuscript.

\section{Availability of data and materials}

All data included in this study are available upon request by contact with the corresponding author.

\section{Declarations}

\section{Ethics approval and consent to participate}

This study was conducted to the ethical guideline of the 1975 Declaration of Helsinki and was approved by the Institutional Ethics Committee of the Mengchao Hepatobiliary Hospital of Fujian Medical University, Eastern Hepatobiliary Surgery Hospital of Navy Medical University, Second Hospital Affiliated to Zhejiang University School of Medicine, First Hospital Affiliated to Army Medical University, Cancer Hospital Chinese Academy of Medical Sciences and Peking Union Medical College, Tongji Hospital Affiliated to Tongji Medical College of Huazhong University of Science and Technology, Beijing Friendship Hospital Affiliated to Capital Medical University, West China Hospital of Sichuan University, Renji Hospital Affiliated to Shanghai Jiaotong University School of medicine, Xuanwu Hospital Affiliated to Capital Medical University, Affiliated Hospital of North Sichuan Medical College, Beijing Tiantan Hospital Affiliated to Capital Medical University, Zhongda Hospital Southeast University. Informed consent was obtained from each patient for their data to be used for research purposes.

\section{Consent for publication}

Not applicable.

\section{Competing interests}

The authors declare that they have no competing interests.

\section{Author details}

${ }^{1}$ Department of Hepatobiliary Surgery, Mengchao Hepatobiliary Hospital of Fujian Medical University, Xihong Road 312, Fuzhou 350025, Fujian, People's Republic of China. ${ }^{2}$ College of Biological Science and Engineering, Fuzhou University, Fuzhou, Fujian, China. ${ }^{3}$ Department of Hepatobiliary Surgery, The Second Hospital Affiliated to Zhejiang University, Zhejiang, Hangzhou, China. ${ }^{4}$ Department of Hepatobiliary Surgery, The Southwest Hospital Affiliated to the Army Medical University, Chongqing, China. ${ }^{5}$ Department of Hepatobiliary Surgery, Cancer Hospital, Chinese Academy of Medical Sciences, Beijing, China. ${ }^{6}$ Department of Hepatobiliary Surgery, Tongji Hospital Affiliated to Tongji Medical College, Huazhong University of Science \& Technology, Wuhan, Hubei, China. ${ }^{7}$ Department of Hepatobiliary Surgery, Beijing Friendship Hospital Affiliated to Capital Medical University, Beijing, China. ${ }^{8}$ Department of Hepatobiliary Surgery, The West China Hospital of Sichuan University, Chengdu, Sichuan, China. ${ }^{9}$ Department of Hepatobiliary Surgery, Renji Hospital Affiliated to Shanghai Jiaotong University, Shanghai, China. ${ }^{10}$ Department of Hepatobiliary Surgery, Xuanwu Hospital Affiliated to Capital Medical University, Beijing, China. ${ }^{11}$ Department of Hepatobiliary Surgery, The Affiliated Hospital of Chuanbei Medical University, Nanchong, Sichuan, China. ${ }^{12}$ Department of Hepatobiliary Surgery, Tiantan Hospital 
Affiliated to Capital Medical University, Beijing, China. ${ }^{13}$ Department of Hepatobiliary Surgery III, Eastern Hepatobiliary Surgery Hospital, Secondary Military Medical University, Shanghai, China. ${ }^{14}$ Department of Hepatobiliary Surgery, Zhongda Hospital Southeast University, Nanjing, Jiangsu, China.

\section{Received: 16 March 2021 Accepted: 7 July 2021}

Published online: 20 July 2021

\section{References}

1. Banales J, Marin J, Lamarca A, et al. Cholangiocarcinoma 2020: the next horizon in mechanisms and management. Nat Rev Gastroenterol Hepatol. 2020;17(9):557-88. https://doi.org/10.1038/s41575-020-0310-z.

2. Fabris L, Sato $K$, Alpini $G$, et al. The tumor microenvironment in cholangiocarcinoma progression. Hepatology. 2021;73 Suppl 1(Suppl 1):7585.

3. Sirica AE, Gores GJ, Groopman JD, et al. Intrahepatic cholangiocarcinoma: continuing challenges and translational advances. Hepatology. 2019;69(4): 1803-15. https://doi.org/10.1002/hep.30289.

4. $\mathrm{Wu}$ L, Tsilimigras DI, Paredes AZ, et al. Trends in the incidence, treatment and outcomes of patients with intrahepatic cholangiocarcinoma in the USA: facility type is associated with margin status, use of lymphadenectomy and overall survival. World J Surg. 2019;43(7):1777-87.

5. Wang $\mathrm{K}$, Zhang $\mathrm{H}$, Xia $\mathrm{Y}$, et al. Surgical options for intrahepatic cholangiocarcinoma. Hepatobiliary Surg Nutr. 2017:6(2):79-90. https://doi. org/10.21037/hbsn.2017.01.06.

6. Waisberg DR, Pinheiro RS, Nacif LS, et al. Resection for intrahepatic cholangiocellular cancer: new advances. Transl Gastroenterol Hepatol. 2018; 3:60. https://doi.org/10.21037/tgh.2018.08.03.

7. Zhang XF, Xue F, Dong DH, et al. Number and Station of Lymph Node Metastasis After Curative-intent Resection of Intrahepatic Cholangiocarcinoma Impact Prognosis. Ann Surg. 2020. https://doi.org/10.1 097/SLA.0000000000003788. Epub ahead of print.

8. Spolverato G, Kim Y, Alexandrescu S, et al. Management and outcomes of patients with recurrent intrahepatic cholangiocarcinoma following previous curative-intent surgical resection. Ann Surg Oncol. 2016;23(1): 235-43. https://doi.org/10.1245/s10434-015-4642-9.

9. Lei Z, Xia Y, Si A, et al. Antiviral therapy improves survival in patients with HBV infection and intrahepatic cholangiocarcinoma undergoing liver resection. J Hepatol. 2018;68(4):655-62. https://doi.org/10.1016/j.jhep.2017.11.015.

10. Clements $\mathrm{O}$, Eliahoo J, Kim JU, et al. Risk factors for intrahepatic and extrahepatic cholangiocarcinoma: A systematic review and meta-analysis. J Hepatol. 2020;72(1):95-103. https://doi.org/10.1016/j.jhep.2019.09.007.

11. Mavros MN, Economopoulos KP, Alexiou VG, et al. Treatment and prognosis for patients with intrahepatic cholangiocarcinoma: systematic review and meta-analysis. JAMA Surg. 2014;149(6):565-74. https://doi.org/10.1001/jama surg.2013.5137.

12. Spolverato G, Yakoob MY, Kim Y, et al. The impact of surgical margin status on long-term outcome after resection for intrahepatic cholangiocarcinoma. Ann Surg Oncol. 2015;22(12):4020-8. https://doi.org/10.1245/s10434-015-44 72-9.

13. Li MX, Bi XY, Li ZY, et al. Impaction of surgical margin status on the survival outcome after surgical resection of intrahepatic cholangiocarcinoma: a systematic review and meta-analysis. J Surg Res. 2016;203(1):163-73. https:// doi.org/10.1016/j.jss.2016.02.012.

14. Farges $O$, Fuks $D$, Boleslawski $E$, et al. Influence of surgical margins on outcome in patients with intrahepatic cholangiocarcinoma: a multicenter study by the AFC-IHCC-2009 study group. Ann Surg. 2011;254(5):824-9; discussion 30. https://doi.org/10.1097/SLA.0b013e318236c21d.

15. Watanabe $Y$, Matsuyama $Y$, Izumi N, et al. Effect of surgical margin width after R0 resection for intrahepatic cholangiocarcinoma: A nationwide survey of the liver Cancer study Group of Japan. Surgery. 2020;167(5):793-802. https://doi.org/10.1016/j.surg.2019.12.009.

16. Hu LS, Zhang XF, Weiss M, et al. Recurrence patterns and timing courses following curative-intent resection for intrahepatic cholangiocarcinoma. Ann Surg Oncol. 2019;26(8):2549-57. https://doi.org/10.1245/s10434-019-07353-4.

17. Lee AJ, Chun YS. Intrahepatic cholangiocarcinoma: the AJCC/UICC 8th edition updates. Chin Clin Oncol. 2018;7(5):52.

18. Mavros MN, Economopoulos KP, Alexiou VG, et al. Treatment and prognosis for patients with intrahepatic cholangiocarcinoma: systematic review and meta-analysis. JAMA Surg. 2014;149(6):565-74. https://doi.org/10.1001/jama surg.2013.5137.
19. Rodrigues PM, Olaizola P, Paiva NA, et al. Pathogenesis of cholangiocarcinoma. Annu Rev Pathol. 2021;16(1):433-63. https://doi.org/1 0.1146/annurev-pathol-030220-020455.

20. Ribero D, Pinna AD, Guglielmi A, et al. Surgical approach for longterm survival of patients with intrahepatic cholangiocarcinoma: a multiinstitutional analysis of 434 patients. Arch Surg. 2012;147(12):1107-13. https://doi.org/10.1001/archsurg.2012.1962.

21. Tang H, Lu W, Li B, et al. Influence of surgical margins on overall survival after resection of intrahepatic cholangiocarcinoma: A meta-analysis. Medicine (Baltimore). 2016;95(35):e4621. https://doi.org/10.1097/MD 0000000000004621

22. Zhang XF, Bagante F, Chakedis J, et al. Perioperative and long-term outcome for intrahepatic cholangiocarcinoma: impact of major versus minor hepatectomy. J Gastrointest Surg. 2017;21(11):1841-50. https://doi. org/10.1007/s11605-017-3499-6.

23. Kang SH, Hwang S, Lee YJ, et al. Prognostic comparison of the 7th and 8th editions of the American joint committee on Cancer staging system for intrahepatic cholangiocarcinoma. J Hepatobiliary Pancreat Sci. 2018;25(4): 240-8. https://doi.org/10.1002/jhbp.543.

24. Lamarca A, Santos-Laso A, Utpatel K, et al. Liver metastases of intrahepatic cholangiocarcinoma: implications for a potential new staging system. Hepatology. 2021;73(6):2311-25.

25. Tang Z, Liu WR, Zhou PY, et al. Prognostic value and predication model of microvascular invasion in patients with intrahepatic cholangiocarcinoma. J Cancer. 2019;10(22):5575-84. https://doi.org/10.7150/jca.32199.

26. Cillo U, Fondevila C, Donadon $M$, et al. Surgery for cholangiocarcinoma. Liver Int. 2019;39(Suppl 1):143-55.

27. Bergeat $D$, Sulpice $L$, Rayar $M$, et al. Extended liver resections for intrahepatic cholangiocarcinoma: friend or foe? Surgery. 2015;157(4):656-65. https://doi.org/10.1016/j.surg.2014.11.011.

\section{Publisher's Note}

Springer Nature remains neutral with regard to jurisdictional claims in published maps and institutional affiliations.
Ready to submit your research? Choose BMC and benefit from:

- fast, convenient online submission

- thorough peer review by experienced researchers in your field

- rapid publication on acceptance

- support for research data, including large and complex data types

- gold Open Access which fosters wider collaboration and increased citations

- maximum visibility for your research: over $100 \mathrm{M}$ website views per year

At BMC, research is always in progress.

Learn more biomedcentral.com/submissions 